\title{
Public Interactive Art: Environmental Challenges
}

\author{
Aphra Shemza \\ Artist \\ Unit I, Arena Design Centre \\ 71 Ashfield Road, Manor House \\ London N4 1FF, UK \\ aphra@aphrashemza.com
}

\section{INTRODUCTION}

"Art is not an end but a beginning" (Hsieh 2008).

This area of research focuses specifically on interactive new media art and how to bring these works out of the gallery and into public spaces, whilst being mindful of their environmental impact. This is the beginning of the research, which will be continued over the course of the next year culminating in an interactive public sculpture.

\section{ARTISTS AS INNOVATORS}

David Galenson (2009) notes: "Important artists are innovators: they are important because they change the way their successors work." Artists lead the way forward, not only for other artists but for all areas of life; architecture, furniture, urban planning, etc.

Artists have always created work using the most radical technology available to them. Technology enables artists to create a dialogue with society in the hope of challenging the way in which the audience perceives or accepts our technological culture.

Interactive new media art is at the forefront of these concerns. The artist strives to create work, which is accessible to everyone, no matter what their age, education or background. In the hope that the work will encourage the passive consumer to become an active part of the piece, embracing notions of dialogue and exchange. Interactive artists challenge the status quo of the art world and of elite institutions, creating artwork that is for the masses.

It would therefore make sense that this work be seen out of the traditional gallery setting to reach as wide an audience as possible. Since the artworks require electricity to run and use the very latest technology, how is it possible to take them to outdoor community spaces whilst taking environmental concerns into account? I will now consider two separate case studies exploring how the artists have addressed these concerns and where they have been successful.

\section{CASE STUDIES}

\subsection{The Hive Wolfgang Buttress}

In June 2016, Wolfgang Buttress installed The Hive, in Kew Gardens (Barrera 2016). The immersive audio-visual structure allows a viewer to be drawn into the world of the bees through data visualisation techniques expressed through sound and light.

The Hive expresses "the plight of honeybees and their value as natural capital" (Bhattacharya 2016). Of the main 100 food crops globally, about 70 are pollinated by bees. The aim of was to portray bees as "a sentinel of the planet, a barometer of the state of the Earth" (Bhattacharya 2016).

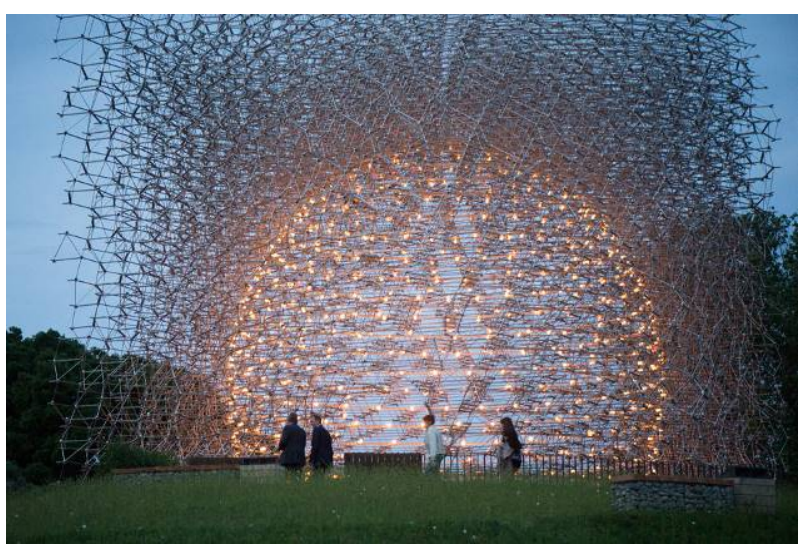

Figure 1: Wolfgang Buttress, The Hive. Image: Jeff Erden. 
The piece itself is magnificent. It is a real work of art and has achieved over 20 awards worldwide, helping to raise awareness of the bees. However, its £6 million cost (Barrera 2016), its use of unsustainable materials, and the fact that the piece must be installed on custom built foundations, mean that the ecological cost of the work is itself high. Has the media coverage and awards that The Hive has received raised enough awareness of the cause to offset the ecological cost of the work?

\subsection{Waste Landscape: Elise Morin and Clémence Eliard}

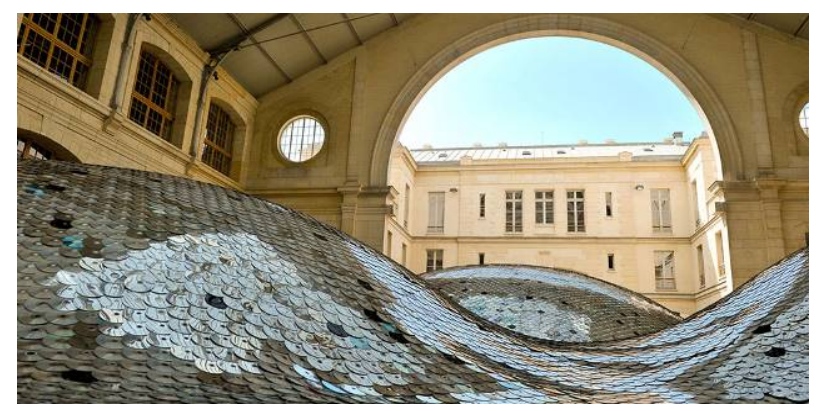

Figure 2: Elise Morin and Clemence Eliard, Waste Landscape.

Image: Yannick Fradin, Martin Eliard \& Marc Sirvin.

Waste Landscape is a " 500 square meter artificial undulating landscape covered by an armor of 65,000 unsold or collected CDs" (Ainsworth 2013). The piece serves to highlight the amount of waste there is in our ever-redundant CD technology soon destined for the landfill and this in turn reflects on our entire consumer culture.

The piece uses donated CDs from Universal Music and the local community and has been built using a group of local volunteers. Once the piece has been shown in Bucharest the CDs will then be recycled, returning the sculptural material back to another use.

Waste Landscape is a brilliant example of how an artwork can work towards being more sustainable in its creation. It is also interesting because after the piece has been exhibited it will be destroyed and will therefore require no further maintenance reducing its environmental impact further whilst bringing to our attention important issues surrounding waste culture.

\section{ENVIRONMENTAL CONCERNS: AT THE HEART OF THE ARTWORK}

This research is not suggesting that every interactive new media artist should create public sculpture that is centred around climate issues. The artists should have the creative freedom to address any concept that they wish. It does suggest however that the artist should be advised to use a set of guidelines made readily available to them, that would help them whilst designing their sculpture to think mindfully about the materials that they are using and what effect their work will have environmentally once it has been installed.

\section{GUIDELINES}

Guidelines would involve the following:

1. Materials:

- How sustainable are they?

- Could you use recycled materials?

- From where do the materials come and what is the carbon footprint of the delivery?

2. Energy

- How will your piece be powered? If it needs electricity can this be powered with solar, wind, water or kinetic energy (made by the viewer themselves) and how might this effect the design choices of your materials or electrical components?

3. Transport

- How will your piece travel from venue to venue?

4. Impact on local environment

- What impact does your piece have on the local environment when being installed? Does it need foundations, etc.?

5. Maintenance

- How much maintenance will your piece need throughout its lifetime, how can this be reduced?

\section{THE FUTURE}

The idea that artists can change the world has become outdated but there is still a necessity to challenge the way in which we perceive things and a need for art to be instrumental in turning society to a new way of thinking (Grynsztejn \& Bal 2007).

Olafur Eliasson believes that "art is a practice through which vital aspects of society and life may be examined, challenged and renegotiated" (Eliasson 2006). It is therefore important that we interactive artists embracing the very latest technology be mindful of the impact that this has on our natural surroundings. I plan to take this research further over the course of the next year whilst designing a large-scale public interactive 
sculpture built around these guiding principles and raise awareness of my journey.

\section{REFERENCES}

Ainsworth, L. (2013) Waste Landscape - Elise Morin and Clemence Eliard. Curating Cities: A Database of Eco Art. http://eco-publicart.org/wastelandscape/ (accessed March 2017)

Barrera, L. (2016) The Hive - Wolfgang Buttress. Curating Cities: A Database of Eco Art. http://ecopublicart.org/the-hive/ (accessed March 2017)

Bhattacharya, S. (2016) Listen to secrets of a honeybee hive in Kew's latest sculpture. New Scientist, 23 June. https://www.newscientist.com/article/2094880-listen-tosecrets-of-a-honeybee-hive-in-kews-latest-sculpture/ (accessed March 2017)

Eliasson, O. (2006) Olafur Eliasson: Your Engagement has Consequences. Baden: Lars Muller Publishers.

Galenson, D. (2009) The Greatest Artists of the Twentieth Century. In Conceptual Revolutions in Twentieth-Century Art. Cambridge, MA: Cambridge University Press.

Grynsztejn, M. and Bal, M. (2007) Take Your Time: Olafur Eliasson. London: Thames \& Hudson.

Hsieh, C (2008) Ai Weiwei, A rebel of Poet Roots. New York Arts Magazine, March-April. 